LHT

40,6

Received 29 February 2020 Revised 30 December 2020 Accepted 1 March 2021

\section{Brain-computer interface in the context of information retrieval systems in a library}

\author{
Magdalena Wójcik \\ Faculty of Management and Social Communication, Institute of Information Studies, \\ Jagiellonian University, Kraków, Poland
}

\begin{abstract}
Purpose - The subject of this paper is the idea of Brain-Computer Interface (BCI). The main goal is to assess the potential impact of $\mathrm{BCI}$ on the design, use and evaluation of information retrieval systems operating in libraries.

Design/methodology/approach - The method of literature review was used to establish the state of research. The search according to accepted queries was carried out in the Scopus database and complementary in Google Scholar. To determine the state of research on $\mathrm{BCI}$ on the basis of library and information science, a specialist LISTA abstract database was also searched. The most current papers published in the years 20152019 in the English language or having at least an abstract in this language were taken into account.

Findings - The analysis showed that $\mathrm{BCI}$ issues are extremely popular in subject literature from various fields, mainly computer science, but practically does not occur in the context of using this technology in information retrieval systems.

Research limitations/implications - Due to the fact that $\mathrm{BCI}$ solutions are not yet implemented in libraries and are rarely the subject of scientific considerations in the field of library and information science, this article is mainly based on literature from other disciplines. The goal was to consider how much BCI solutions can affect library information retrieval systems. The considerations presented in this article are theoretical in nature due to the lack of empirical materials on which to base. The author's assumption was to initiate a discussion about $\mathrm{BCI}$ on the basis of library and information science, not to propose final solutions.

Practical implications - The results can be widely used in practice as a framework for the implementation of $\mathrm{BCI}$ in libraries.

Social implications - The article can help to facilitate the debate on the role of implementing new technologies in libraries.

Originality/value - The problem of $\mathrm{BCI}$ is very rarely addressed in the subject literature in the field of library and information science.
\end{abstract}

Keywords Brain computer interface, Information retrieval systems, Information services, Innovation,

Libraries

Paper type Viewpoint

\section{Background}

Brain-Computer Interface (BCI) is a collective name for technologies focused around providing the ability to operate electronic equipment via using brain waves. At the core of BCI development are studies on the brain's electrical activity and the development of encephalography techniques. As Ramadanand and Vasilakos stated: "Brain Computer Interface (BCI) is defined as a combination of hardware and software that allows brain activities to control external devices or even computers" (2017, p. 26). Research on the possibility of using BCI began with animal studies, but quickly moved to human research and started to develop

(C) Magdalena Wójcik. Published by Emerald Publishing Limited. This article is published under the Creative Commons Attribution (CC BY 4.0) licence. Anyone may reproduce, distribute, translate and create derivative works of this article (for both commercial and non-commercial purposes), subject to full attribution to the original publication and authors. The full terms of this licence may be seen at http:// creativecommons.org/licences/by/4.0/legalcode

Author would like to thank Mike Timberlake for proof-reading. 
particularly rapidly at the beginning of the twenty-first century. The potential of such interfaces is extraordinary, especially as a technology that facilitates the communication processes and use of electronic resources for people with physical disabilities, including, for example, people with paralysis, as well as in the form of less or more invasive implants to improve or restore sensory and motor skills to people (Pichiorri et al., 2015; Vansteensel et al., 2016). As Mason and Birch stated, the ultimate goal of developing BCI is to provide people with severe degrees of disability the ability to operate various types of electronic equipment, which would significantly increase their communication possibilities and the overall comfort of their lives (2003). Due to its enormous social value, this issue is the subject of intense consideration in many disciplines, mainly IT and medical research, but remains almost neglected as an area of interest for library and information science. This gap in research should be fulfilled. The thesis of this paper is that $\mathrm{BCI}$ can have a potentially large impact on the approach to the design, use and assessment of the usability of information and search systems used in libraries, and therefore it is a topic worth considering in the field of information and library science.

\section{BCIs - technical and practical aspects}

This paper focuses on discussing the concept of BCIs and the theoretical analysis of their applicability in libraries, not on a detailed discussion of technical and implementation aspects that are covered in many studies in the field of computer science. Nevertheless, some basic technical issues related to the operation of BCIs need to be clarified.

As noted in the definition of $\mathrm{BCI}$, this technology is based on the most general sense on the use of impulses generated by brain waves to influence electronic devices so that they can be controlled and used without manual intervention. As Sullivan and Illes stated: "BCI devices involve direct communication between the central nervous system (CNS) and external devices. Unlike transcranial direct current stimulation (tDCS), deep brain stimulation (DBS), and transcranial magnetic stimulation (TMS), which stimulate the brain based on pre-established settings, BCIs measure CNS activity and respond with artificial outputs that replace, restore, enhance, supplement, or improve natural CNS output, either directly through the CNS or via a prosthetic device" (Sullivan and Illes, 2016). Reading brain activity can be done in different ways and so BCIs are developed as both invasive and non-invasive forms (Chaudhary et al., 2016). Non-invasive methods are mostly based on the assumptions of electroencephalography, while invasive methods assume the use of partially and completely invasive implants of different types. One of the broadest and most dynamic developing fields of application of BCIs is medicine, especially the treatment of people with various degrees of paralysis, up to and including the locked-in syndrome. In the case of medical applications, BCIs are particularly associated with the concept of neurobionics, defined as: "(...) science of directly integrating electronics with the nervous system to repair or substitute impaired functions" (Rosenfeld and Wong, 2017, p. 363). In the case of BCI, the connection of the brain and electronic devices takes place through: "(. . ) scalp, subdural or intracortical electrodes" (Rosenfeld and Wong, 2017, p. 363). It is worth noting that less invasive solutions such as electrocorticography that uses electrodes placed in the subdural space or electroencephalography based on scalp electrodes are, according to some authors, less precise than invasive solutions, for example those that are based on penetrating microelectrodes, however, they are easier to carry out and often safer for the users (Rosenfeld and Wong, 2017). As Merrill and Chuang stated: "Non-invasive, consumer $\mathrm{BCIs}$, are lightweight, require minimal setup, and do not require special gels. EEG (electroencephalography) is currently the most viable choice of sensing modality for consumer BCIs" (Merrill and Chuang, 2018, p. 1). The quoted statements show that for both non-invasive and invasive solutions there are pros and cons that must be taken into account. It is also worth noting that: "While the non-invasive devices allow home use, they still require supervision by highly competent research personal. Home use of invasive BCIs is not yet

\section{Brain- computer interface in a library}

1767 
LHT

40,6

1768

feasible (...)" (Chaudhary et al., 2020, p.7), which is an important factor influencing the practical use of this technology.

When discussing the practical aspects of BCIs operation, attention is often paid to issues related to technical problems, e.g. biocompatibility of used materials, efficiency and sustainability of the solutions adopted and their safety. This is especially important in the case of invasive solutions, where the quality of the nanomaterials used, for example equipping them with anti-inflammatory coatings, is crucial. Therefore, when choosing BCI technical solutions, it is necessary to think over and weigh the pros and cons of various solutions. For the use of library applications for non-disabled users, solutions based on noninvasive methods seem to be the right choice, for disabled users the choice depends on their particular needs and their medical condition.

\section{Objectives and method}

The subject of this article is non-invasive BCI forms for controlling electronic devices using brain waves, especially in the information retrieval systems. Other forms of BCI will not be considered in this article, including partially and completely invasive implants aimed at restoring sensory performance, as this is a separate, broad topic. The main goal is to determine the potential influence of $\mathrm{BCI}$ on design, use and evaluation of information retrieval systems used in libraries. The specific goals include: identifying current areas of BCI use and its potential for future use, characterizing information retrieval systems' types, features and applications and describing $\mathrm{BCI}$ potential for developing libraries' information retrieval systems.

The method of literature review was used to establish the state of current research. The search according to selected queries was carried out in the Scopus and Web of Science databases - key databases indexing journals with high Impact Factor and complementary in Google Scholar - the popular search engine of scientific resources. To determine the state of research on $\mathrm{BCI}$ on the basis of library and information science, a specialist LISTA (Library, Information Science and Technology Abstracts) database was also searched. Due to the abundance of publications only the most current papers published in the years 2015-2019 (first half of the year 2019) in the English language or having at least an abstract in this language were taken into account. The detailed process of searching for publications is presented in Table 1.

The analysis showed that BCI issues are extremely popular in subject literature from various fields, mainly computer science and medicine, but practically does not occur in the context of using this technology in information retrieval systems. The search carried out in Scopus showed a large abundance of BCI-related publications, which can be divided into several basic categories according to the area of research (Figure 1).

Of the 7,288 publications found, most can be classified as computer science research 4,283, engineering - 3,326, neuroscience - 1,698, medicine - 1,378 and mathematics - 1,048. These issues were definitely less frequently raised in arts and humanities - only 63 were

\begin{tabular}{lll}
\hline Source & Query & Results \\
\hline Scopus & In title, abstract and keywords "brain-computer interface" & Results: 7,288 \\
Web of Science & In topic: "brain-computer interface" & Results: 4,415 \\
& In title: "brain-computer interface" & Results: 1,225 \\
Google Scholar & "brain-computer interface" allintitle "brain-computer interface" & Results: 18,700 \\
& & Results: 2,110 \\
LISTA & "brain-computer interface" & Results: 12 \\
& In title: "brain-computer interface" & Results: 2
\end{tabular}

Source(s): Own research 


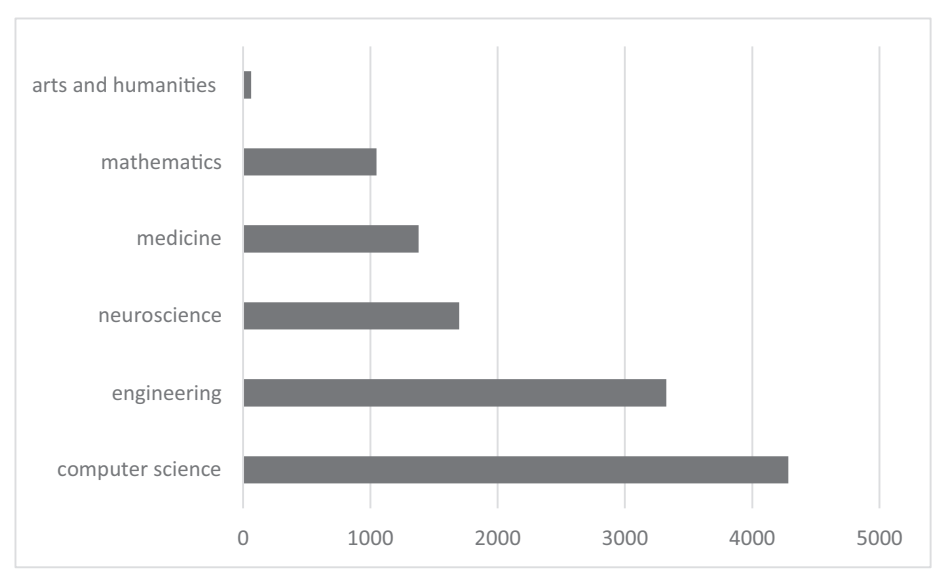

Source(s): Own drawing based on Scopus analytical options

\section{Brain- computer interface in a library \\ 1769}

Figure 1.

BCI state of research in Scopus according to the field of research

classified that way in Scopus. Noteworthy is the increase in the popularity of BCI issues over the years 2015-2019 that were examined. In 2015, 1,411 papers were published, in 2016 1,445, in 2017 - 1,622 and in 2018 the most, 1,713. In 2019 on the day of reading (11 August 2019) 1,097 articles were recorded. By the end of 2019, this number may still increase (Figure 2).

These conclusions are confirmed by a search of Web of Science. The phrase "braincomputer interface" appeared 4,415 times in the topic of publication, and 1,225 in the title. Of the works that included BCI in the title, the most took the form of article 608, but this topic was often raised in conference proceedings - 546 times. Among the publications found, works written from the point of view of computer science -565 , engineering - 331 and neuroscience - 297 predominated (Figure 3).

In the analysed period, publications indexed in Web of Science containing the phrase "brain-computer interface" in the title were most often published in the year 2017. It can be

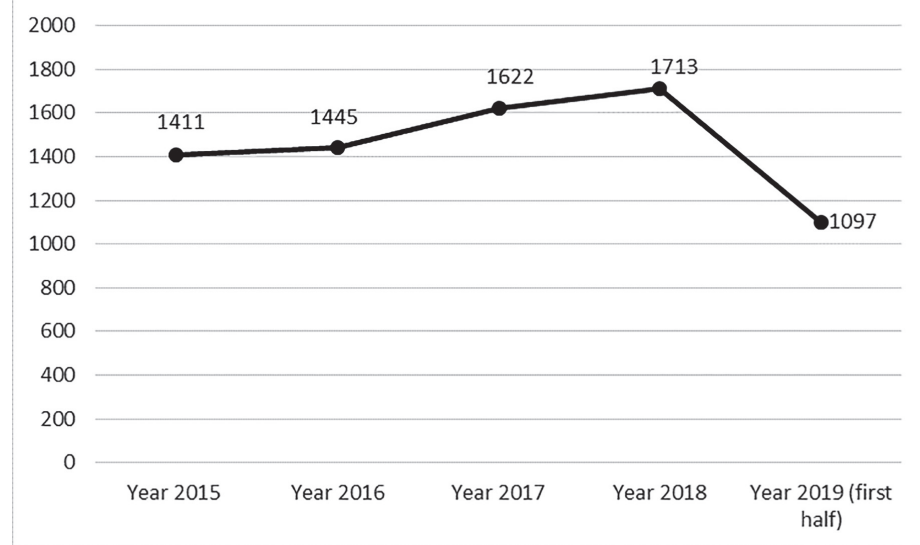

Figure 2. BCI state of research in Scopus according to the year of publication

Source(s): Own drawing based on Scopus analytical options 


\section{LHT 40,6}

\section{0}

Figure 3.

BCI state of research in Web of Science according to the field of research
Figure 4.

BCI state of research in Web of Science according to the year of publication

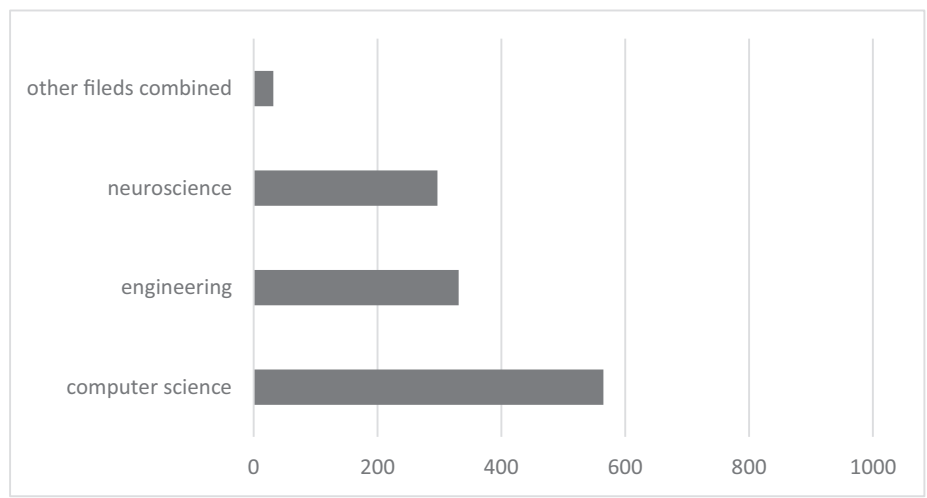

Source(s): Own drawing based on Web of Science analytical options

seen that in the 2015-2019 period, the number of publications fluctuate and it was once a little bigger, once a little smaller. In the first half of 2019 exactly half of the works from 2018 were published (Figure 4).

In order to deepen the analysis, the most cited authors were selected. According to Scopus, these are: D. Ming, S.W. Lee, C. Guan, J. Jin, Y. Wang, T.P. Jung, X. Wang, C. Guger, D. Farina and N. Birbaumer. According to Web of Science database: Y. Zhang, J. Jin, C. Guger, S.W. Lee, X.Y. Wang, K.S. Hong, C.T. Lin, C.T. Guan and Y.Q. Li. The comparison of the results from both databases shows that the names of the most frequently cited authors overlap to a large extent, but not entirely. For example, the most cited author in Scopus D. Ming does not appear in the Web of Science top cited authors list. This shows that doing complementary analyses in both databases is advisable to obtain complete information.

In order to further deepen the analysis, the top 10 most cited articles from Scopus (Figure 5) and Web of Science (Figure 6) were identified, the keywords noted from these articles, assuming the principle that the author's keywords are taken into account or, in the absence of them, the words from the first cited keyword classification and the results are

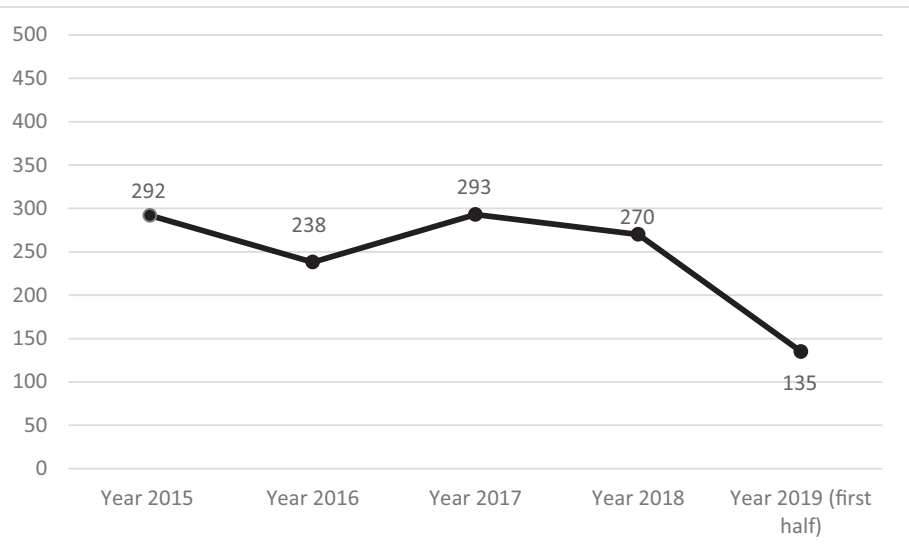

Source(s): Own drawing based on Web of Science analytical options 


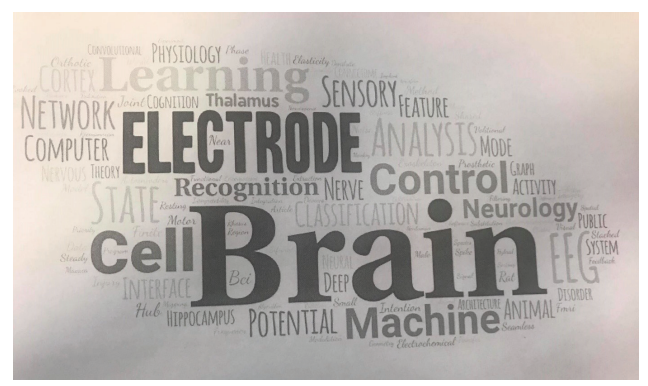

Source(s): Own research based on the analysis of the subject literature, visualisation: wordart.com

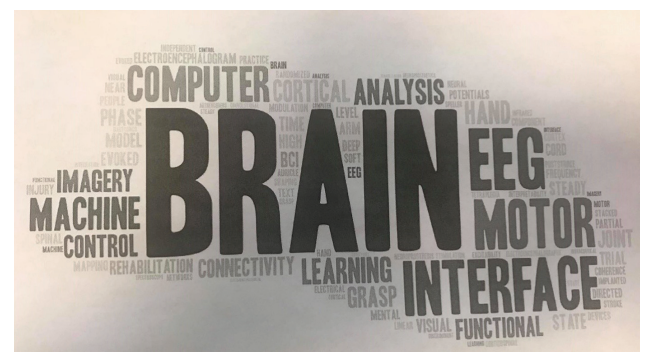

Source(s): Own research based on the analysis of the subject literature, visualisation: wordart.com
Braincomputer interface in a library

1771

Figure 5.

Word cloud based on

Scopus

Figure 6.

Word cloud based on

Web of Science

compiled in the form of a word clouds. Keyword analysis of the most cited articles confirms previous analyses related to research areas. Advantage of keywords in the field of neuroscience and medicine, as well as computer science can be noted. There are also keywords related to social science education and psychology, although less frequently.

Presented conclusions based on Scopus and WoS databases are confirmed also by the search carried out at Google Scholar - here also publications written from the perspective of computer science, engineering and medical sciences as well as mathematics prevailed. In total, it was possible to search over 18,000 publications in the adopted time range, but publications that addressed the topic of BCI as the main were already less than just over 2,000. Interesting results were shown by a search carried out in LISTA, a specialized abstract database in the field of library and information science. Here, there were 12 results related to the subject, and only 2 results that contained the phrase brain-computer interface in the title: "Behaviour state analysis through brain-computer interface using wearable EEG devices: a review" (Ramakuri et al., 2017) and "A brain-computer interface for the Dasher alternative text entry system" (Welton et al., 2016), which confirms the thesis about the low popularity of these issues in the field of research of library and information science.

\section{BCI - current areas of use}

One of the most promising and most often described practical applications of BCI is the application in medicine, and specifically with regard to solving problems of people with physical and sensory disabilities - after strokes, with partial or complete paralysis, muscle wasting and other similar, often very serious ailments. Reflections on this topic are conducted 
LHT 40,6

\section{2}

in two main streams - the first: how mostly non-invasive or partially-invasive BCI-based interfaces can facilitate access to information for patients, as well as enable them to communicate better, the second topic: whether invasive BCI elements, e.g. implants implanted in patients, can help to restore or at least improve their health (Pichiorri et al., 2015; Vansteensel et al., 2016). As mentioned before, the topic of the use of $\mathrm{BCI}$ in medicine is very popular and discussed in detail on many levels and in many departments of medical research, but due to the lack of a direct connection of this issue with the topic discussed in this paper, these topic will not be thoroughly analysed. It is worth emphasizing that, as pointed out by Lawhern et al., BCI has potential not only for patients but also for healthy people, by increasing their communication and cognitive abilities, most often with the use of noninvasive forms of BCI (2018). Beyond medicine, important field of BCI application are education and self-improvement. For instance, interesting research conducted by Verkijika showed that BCI can potentially be a useful tool in developing cognitive functions necessary for children to master mathematical competence (2015). It can be assumed that BCI may also be available in training other types of competences on different stages of education and in this way it can be useful in library services. For example, BCI may potentially support reading instruction and the development of users' information, reading and media competences. What is more, $\mathrm{BCI}$ creates a field for the development of new types of interfaces, and thus the opportunities for design of completely new quality of entertainment, mostly in regard to games (Kang et al., 2016; Vasiljevic et al., 2018), including so-called serious games which use the game mechanics as powerful teaching tool (Monaco et al., 2019). Of course, BCI is also used in the broadly understood commercial sector - both in industry and engineering (Angrisani et al., 2018), for instance in the context of using BCI to control robots or other mechanical elements of construction or production process (Hortal et al., 2015), as well as in business and services (Orenda et al., 2017); however, these applications are not still widely described in the scientific literature (Figure 7).

\section{Library information retrieval systems - types, features, applications}

Information retrieval system can be broadly defined as every system which produce of the input information - usually the query expressed by the user-output information - ideally,

Figure 7.

Current areas of $\mathrm{BCI}$ use

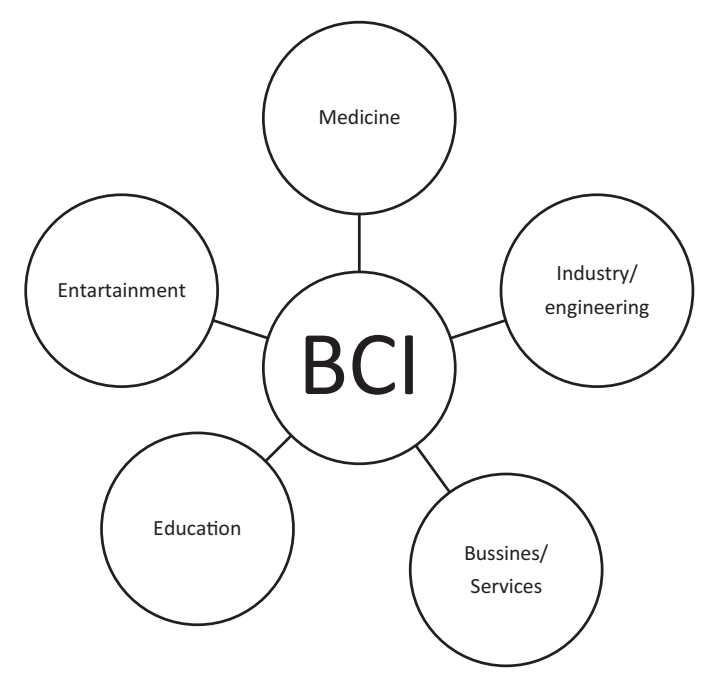

Source(s): Own research based on the analysis of the subject literature 
which responds to the reported query. As Gupta et al. stated the main goal of creating information retrieval systems is to provide users the chance to search for relevant information in large data sets in a short period of time (2015). Technical aspects, appearance and functionality of the system can occur in many variants; however the basic purpose of information retrieval systems is to meet users' information needs by enabling easy selection of relevant information from a large collection.

A few basic types of information retrieval systems can be distinguished in the library: electronic catalogs (so-called OPACs-Online Public Access Catalogs), own library databases (e.g. bibliographies, thematic lists, databases related to the region, prepared by librarians) and databases purchased by the library from external suppliers (primarily publishers of scientific books and journals).

The basic functionalities of OPAC catalogs include search for resources options according to various criteria, most often with the help of simple and advanced searching tools, as well as browsing options. Another popular feature is ordering/booking option for selected resources that allows users to quickly receive previously selected and reserved materials in the library. Sometimes catalogs also provide direct access to, for instance, tables of contents, abstracts, fragments of books or even electronic versions of publications. The systems also send reminders about the upcoming date that publications must be returned to the library and provide the option of extension of the loan period online. Some catalogs have also social media-like options and provide users the ability to add book ratings, write reviews or discuss with librarians and other users (Gupta, 2018) - but these solutions are still not widely used in libraries' catalogues.

The variety of information retrieval systems prepared independently by librarians is huge and depends largely on the specificity of the local library and the needs of its users. An example could be local bibliographies, thematic lists and databases for educational purposes or databases related to the particular region. The design, appearance and searching mechanisms of this resource type vary, but like library catalogs, they usually include options for searching and browsing resources, including using indexes. On the other hand, databases purchased by the library from external suppliers they are the most standardized and usually have similar functionalities geared to finding scientific information. Simple and advanced search options, options for constructing custom search queries using logical operators and the ability to view resources by different formal and content categories allow access to resources stored in the database.

Designers of modern library systems in general, regardless of the type of database, place great emphasis on systems' information architecture and user-friendliness. There is extensive literature of the subject regarding issues such as the construction of library systems, their usability and friendliness or social options in library systems and websites that enabling users to co-create the system (Parkes and Walton, 2010; Chow and Croxton, 2014; ChanLin and WeiHsiang, 2016). The most frequently mentioned postulates include creating a clear, transparent information architecture, providing users the ability to easily search for content using simple queries and natural language, ensuring the possibility of co-creating and sharing resources and ensuring that the overall user experience associated with using the system is positive, memorable and unique (Priestner and Borg, 2016). The enforcement of these principles in practice is not always perfect, but there has been more emphasis in recent years on this issue.

\section{$\mathrm{BCI}$ in design of information retrieval systems}

A lot has changed in the last several years when it comes to designing library systems. New design trends, such as minimalism, tile design and flat design are slowly beginning to seep into the sphere of library resource design changing both the appearance and functionality of the systems. Also more avant-garde concepts such as the "no-interface", approach

\section{Brain- computer interface in a library}


LHT

40,6

propagated by Krishna, which postulates a total departure from artificially created interfaces in favour of natural and almost unnoticed organization of human interaction with resources (2015), also have an impact - albeit less - on the way of thinking about designing resources and systems in libraries. Designers began to think more often in terms of designing user experience, and thus creating a comprehensive, positive, purposefully designed user experience, including that in the library (Priestner and Borg, 2016). It was postulated, especially in the commercial services sector, to include the user in the design processes and design a holistic "users' journey" taking into account their emotions in order to increase their future loyalty and involvement in the final product-system (Reason et al., 2015). Engaging users in design processes fits well with another factor influencing the design of library systems, namely Web 2.0, network model based on blurring the boundaries between content creator and the recipient that is, to varying degrees, implemented by libraries (Boateng and Liu, 2014). Users, including those in the library, expect the availability of co-creation of resources, which also forces on libraries the use of new design approaches based on building user engagement and loyalty through cooperation with them (Young and Rossmann, 2015).

Not only new trends in design but also the broadly understood the development of new technologies have an impact on library information systems. Development of mobile technologies, especially those based on technologies such as virtual or augmented reality influenced the way of designing at least some types of library systems and applications. Creating completely artificial, digitally generated worlds as it is in virtual reality or blurring the boundaries between the world of real and digital objects as in the case of augmented reality create completely new possibilities for the design of electronic resources and systems (Avila, 2017). Just like the technologies and design trends mentioned earlier, BCI can also be considered as a new approach to interface design and that's why it's worth thinking about how this trend can affect the design process of library systems.

In the case of external databases, most often purchased by the library from large publishers on a license basis, the library does not have a great impact on the database interface, but it is interesting to consider the options offered by information databases created by libraries or online catalogues often adapted to the needs of a particular library by the entities that provide them.

Nowadays, the whole idea of interface design is based on standard assumptions - the user communicates with the system and receives feedback using elements of information architecture, visual layer and search elements of the system using standard commands transmitted via the keyboard, mouse or touch screens, occasionally also via using voice commands. But what if the user is not able to use his body or voice to communicate with the system? Here BCI may be the solution. BCI design is based on completely different assumptions than designing standard interfaces. The idea of BCI assumes that humansystem communication is done by reading and processing brain waves. In this way, the system can be controlled without using the body or voice of the user but only through the activity of his brain (Ramadanand and Vasilakos, 2017). It seems reasonable to say that since the way the system operate is changed, its process of design must also change, so that it is better adapted to a particular way of operating such systems, the more so that the control of brain waves may not be as precise and fast as, for example, simply clicking the mouse on a specific point on the screen. All BCI features that positively and negatively distinguish these interfaces from others must be taken into account when designing BCI-based library systems. It seems that such interfaces should above all be maximally readable and simplified because they will be used mainly, but not only, by people with various levels of disability. Due to the limited precision of manoeuvring the interface via brain waves, at least in the early stages of use where the user is not accustomed to the system, it is necessary to maintain appropriate distances between the elements of the system and enlarge them. It seems that due to the specificity of use, the BCI must be simpler and clearer compared to the standard one, and 
because of that the entire service information architecture should be rethought. Existing library systems cannot be simply translated into $\mathrm{BCI}$, they must be redesigned and adapted accordingly. It seems that currently the level of interface perfection in terms of their design is relatively low. Some researchers argue that BCIs are not widespread due to, among others, their overall poor user-friendliness (Weyand et al., 2015). It can be assumed that rethinking the $\mathrm{BCI}$ design phase is particularly important for their successful practical implementation in libraries. Keeping in mind the challenges that accompany BCI design, it is worth paying attention to the benefits. Designing interfaces in a way that aims for maximum simplicity and readability, which is forced by the specificity of $\mathrm{BCI}$, can have long-term and positive effects not only for the design of systems for people with disabilities but also for all users. Perhaps $\mathrm{BCI}$ will encourage the general simplification of library systems, making them more transparent and user-friendly for all users. This is certainly an opportunity to rethink the principles of designing library systems in a more general way, which can be beneficial for both users and librarians.

\section{$\mathrm{BCI}$ in use of information retrieval systems}

$\mathrm{BCI}$ is completely different from the standard philosophy of creating information retrieval systems, and hence the practical aspects of BCI use, related mainly to searching, browsing or selecting information, will be different. BCI is not based on the use of standard external computer components such as a keyboard or mouse, it is more similar to the idea of voice control, but instead of vocal signals, signals sent by brain waves are recognized (Ramadanand and Vasilakos, 2017). From the user's point of view, such an interface can be more intuitive and natural as their thoughts translates directly into actions. BCI can be seen in this context as an interesting variant of the world as an interface concept according to which the user should interact with information resources in an intuitive, natural and almost imperceptible way with as little external distractions and artificial components as possible (Olsson et al., 2012). Brain waves translating the user's intentions directly from his/hers mind to an electronic device can be considered as such natural way of interaction. On the other hand, using BCI requires getting some used to it due to the very different design and pragmatics of use of this type of interfaces compared to the standard ones. This may, for example, cause problems with the precision of actions performed, problems in understanding the principles of operating BCI or quick fatigue of the user during system use, especially during a long or complicated information retrieval process. Abdulkader et al. also pointed out possible usability and technical problems that may be connected with using BCI (2015), among others problems with proper read and interpretation of brain waves by BCI as well as problems with removing information noise and interference in the transmission of information. In this context, training users' information and media competence, defined as: "(. . .) ability to search for, select, critically evaluate and use information for solving problems in various contexts" (Limberg et al., 2012, p. 96), seems to be particularly important in implementing BCI so they can understand the challenges associated with using $\mathrm{BCI}$ and they were able to deal with this specific type of information transfer. There is certain that possessing knowledge and practical skills in the use of information and search systems, searching, analysing and selecting information, as well as skills in operating new technologies is necessary to effectively use BCI.

Another context that should also be considered when discussing the pragmatics of using $\mathrm{BCI}$ is the specificity of the users themselves. It must be remembered that $\mathrm{BCI}$ systems are particularly often, however not only, used by people who cannot use traditional interfaces, most often for health reasons (Pichiorri et al., 2015; Vansteensel et al., 2016). Such users will have specific problems, needs and expectations, therefore their specific conditions will affect the pragmatics of service use. In the case of $\mathrm{BCI}$, it seems particularly important to be able to personalize the interface design, and thus personalize its use. Again, as in the case of BCI

\section{Brain- computer interface in a} library 
LHT

40,6

design problems, this can be seen as a weakness of such systems, but it can also be viewed as an opportunity for libraries to pay more attention to personalization of services as an important element of their quality. Focusing on the use of BCI can thus draw attention to wider problems related to the design of library systems and services bringing positive changes in the long run.

\section{$\mathrm{BCI}$ in evaluation of information retrieval systems}

The methodology of testing traditional interfaces for their usability is well developed. The most popular approaches include: functionality tests, heuristic evaluation, interviews and focus groups, $\mathrm{A} / \mathrm{B}$ tests or eye tracking. However, the issue of their usefulness for the $\mathrm{BCI}$ study requires consideration, the reason being that BCIs are specifically designed and operated. Because the pragmatics of use is different than in standard systems, it can be assumed that also criteria for assessing the quality of BCI-based services and methods for testing their functionality will be slightly different.

The first method worth considering in the context of $\mathrm{BCI}$ is classic functional tests involving users. The idea of such tests is based on observing users while they perform practical tasks typical for the tested system. Tests are carried out by so-called moderator who conducts the session, but should also be recorded, e.g. in the form of audio, video or by registering mouse movements on the screen, as well as observed live by one or several people invisible to the person taking part in the study, e.g. sitting behind a Venetian mirror (Krug, 2014). Tests are often preceded or followed by a survey and/or user interview. It seems that the very principle of conducting functional tests may work in the case of BCI testing, but tasks for users must be different, testing key factors for the functionality of BCI systems, for example, the effectiveness of the use of popular BCI tools such as spellers. In addition, the setup must be adapted, e.g. users, often for health reasons, may not sit directly at the computer, but at a certain distance from it (Garcia et al., 2015). Moreover, registration methods must be adapted, e.g. there is no mouse whose movements can be registered, also the user focused on using the system may not provide feedback in vocal form or they may not be able to comment because of their disability.

Another popular method, heuristic evaluation, is carried out by experts who assess the system in terms of adopted criteria. The very assumption of heuristic analysis may find application in BCI studies, but the criteria taken into account in the assessment must be adapted to the specifics of such interfaces. Taking well-known J. Nielsen's heuristics as an example, it can be analysed how they could be adapted to the BCI study. According to Nielsen well-designed system should clearly inform users about everything that is going on through appropriate feedback, use language that is understandable and familiar to the user, give the user the ability to easily back out if they make a mistake and - when possible - preventing users from making mistakes, be designed in a consistent and standardized manner, be userfriendly and easy to learn, be flexible and efficient, be aesthetic in design, be equipped with help systems and appropriate documentation of the system (Nielsen, 1994). When referring these heuristics to testing BCI systems on one hand, many general demands still remain valid - the system should still be understandable, flexible, friendly or easily memorized, however, these postulates will probably be implemented differently in BCI systems from the standard interfaces, which is why the researchers will have to be sensitive to other criteria for measuring success in the implementation of specific heuristics. For example, transparency or aesthetics will mean something different in a traditional system and something different in $\mathrm{BCI}$ and similarly, it will be necessary to create some new standards for the assessment of already known heuristics.

Performing usability studies using interviews and focus groups, as it is often done in testing traditional systems (Koskela et al., 2015; Kauppinen et al., 2017), may in some cases be used in the BCI study, but not always, it all depends on the user's health. BCIs are most often designed 
for people who, due to their health condition, cannot use the systems in a standard way - very often they are also people who cannot use voice communication, let alone conduct interview in a vocal form. These forms of usability studies can be adapted to the condition of specific users, e.g. interviews can be performed in a simplified model based on the yes/no options or conducted in written form if user's health allows it. As in the previously discussed cases, also in the case of interviews or focus groups, the questions asked must be adapted to take into account the specificity of the system under examination, as well as the specific needs of its users.

Among other popular methods: A/B testing and thus checking the functionality of different versions of the system by users (Siroker and Koomen, 2013) can be successfully used for BCI testing without major adaptations. Eye tracking can be interesting method in some respects if eyeball movements can be associated with brainwave operations. In this context, the effectiveness and accuracy of $\mathrm{BCI}$ could be examined on the basis of eye-ball movements symbolizing the user's intention and the result in the form performed by the system of operations.

To sum up, it seems that many methods known from usability testing of traditional interfaces can also be used in BCI studies. However, adaptations in the procedures are required to take into account both the specificity of the interfaces tested and the specificity of their users.

\section{Discussion}

There is no doubt that BCI has great potential for many areas of human activity, as well as for scientific research in many disciplines. As with any technology, however, all pros and cons should be considered. In the case of $\mathrm{BCI}$, consideration is primarily given to issues such as security of use, data security and legal and ethical aspects. As Burwell et al. pointed out: "The potential widespread use of $\mathrm{BCI}$ raises interesting questions about moral and legal responsibility (...) argument is over whether the unique characteristics of $\mathrm{BCI}$ will require changes to our legal systems and understanding of morality" (2017). Concerns regarding ethical and legal issues are most often raised in the context of BCI invasive solutions that interfere with the user's body, most often for medical purposes. In such cases, care must be taken to ensure that the patient is aware of all the positive and negative consequences of using BCI implants and that the decision he makes in this regard is fully aware and thoughtout. Some authors also pointed out that although BCI solutions are currently used mainly in medicine to help the disabled and sick people, there may be pressure on doctors in the future to use technical solutions underlying BCI to increase the capabilities of healthy people. It is mentioned among others: "memory augmentation, cognitive enhancement, infrared vision and exoskeletal enhancement of physical performance (...)" (Rosenfeld and Wong, 2017, p. 366), which may raise legitimate concerns and controversies as to the social effects of selectively increasing the cognitive and physical abilities of some people. There seems to be no way to tackle these problems other than by developing international, clear guidelines and regulations that clarify the circumstances and conditions of using BCIs.

Although the use of invasive implants arouses a lot of controversy, discussions also arise in the case of non-invasive ones. Due to the specifics of using this type of solutions, also in this case it should be ensured that the user understands and accepts the principles of BCI. In this context, it seems necessary to develop legal and ethical solutions that protect BCI users. The development of satisfactory legal and ethical solutions requires close cooperation between lawyers and specialists in various fields: IT specialists, philosophers, medical professionals, but also information specialists, including librarians. It is extremely important that the librarian community follows new trends, such as BCI, and actively engages in discussions about them, as well as participates in developing vital solutions. This may be a chance to promote the librarian profession and show librarians in new roles as consultants, innovators, activists and defenders of users' rights.

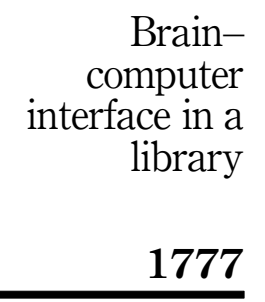

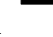


LHT

40,6

Another raised problem is the aspect of conducting empirical research with the use of $\mathrm{BCI}$. Conducting this research is extremely important to the development of this technology, but requires following rigorous research procedures and ethical guidelines, as pointed out by Sullivan and Illes. The authors postulate that future research on this topic should include the following components: "(1) A statement explaining the choice of subject (2) A statement of risk-benefit (3) Citations supporting claims about target population desires, needs, and/or values (4) Recognition of the multiple possible uses of the BCI device being tested, including related opportunities and caveats" (Sullivan and Illes, 2016, p. 162).

In the literature on the subject not only ethical and legal issues are raised but also important matters related to data security. Ienca and Haselager pay attention to safety issues related to the use of $\mathrm{BCI}$ implants. According to the authors, this type of solutions are vulnerable to cybercriminals' attacks and we can talk about the threat of "neurocrime" based on so-called brain-hacking. As authors stated: "The term brain-hacking refers to the emerging possibility of coopting brain-computer interfaces $(\mathrm{BCI})$ and other neural engineering devices with the purpose of accessing or manipulating neural information from the brain of users" (Ienca and Haselager, 2016, p. 117). The threats arising from these types of attacks are difficult to imagine - from data loss, through information manipulation, to attempts to control human behaviour. As Merrill and Chuang pointed out development of BCI may cause anxiety in people, for example, fear of leakage of private information, and even - taking into account the specificity of this technology and its dynamic development - possibility of unauthorized access to other people's thoughts (Merrill and Chuang, 2018).

It remains to be hoped that in the case of BCI solutions, as in the case of other interfaces, appropriate and effective safeguards will be developed to limit the risk of such attacks. It is also important to conduct information campaigns and educational activities that will ensure that users can use BCI solutions safely and responsibly. This is where librarians can play an important role by shaping such specific information competences and by including BCI issues in the scope of information literacy education.

Summarizing, it seems that the topic of using BCI should be approached with caution in view of ethical, legal and criminal threats. The above-mentioned examples show the areas of threats rather than propose ready solutions. This is due to the complexity of the problems discussed and the need to discuss how to prevent them in a wide range of scientists and practitioners from various fields. This is not an easy problem, and there are no easy answers. However, given the great utility of BCI, especially in the field of medical sciences, further development of this type of interface can be expected despite the diagnosed threats. It seems that BCI can also have a large and potentially positive impact on the way library systems are designed, used and assessed. The specificity of $\mathrm{BCI}$ forces the use of non-standard solutions in the above-mentioned areas, aiming at maximum simplicity, readability and personalization of library systems. These postulates, if implemented under the influence of changes brought by BCI, may have a broader impact on the way of thinking about library systems and services, making them simpler and more user-friendly.

It seems necessary to conduct a lively discussion both among theoreticians from various research fields and among practitioners in order to jointly work out solutions to the diagnosed problems and to use the full potential of BCI so that it can stimulate positive processes and changes in libraries, encouraging a non-standard and fresh way of thinking.

\section{Conclusions}

The analysis showed that $\mathrm{BCI}$ issues are extremely popular in subject literature from various fields, mainly computer science and medicine, but practically does not occur in the context of using this technology in information retrieval systems. It seems that this gap in research should be filled on the basis of library and information science, and in a broader context - BCI issues should become a more frequently discussed object of research in social sciences and 
humanities. In order to increase the pool of scientific research on BCI in library and information science, it is necessary to practically introduce such interfaces to libraries and to conduct empirical studies with users to check the effectiveness of these solutions for library purposes. It would be very interesting to examine the usefulness and friendliness of BCI from the point of view of library users, as well as to carry out heuristic analysis by experts according to adapted assessment criteria. It seems that BCI may open some new research perspectives for library and information science and may also become a fertile field for interdisciplinary research. It can be concluded that the possible use of BCI in library systems can significantly affect not only research but also the processes of design, use and testing library information retrieval systems. It is worth looking at these issues now so that the future introduction of BCI to libraries was carried out smoothly and for the benefit of both users and librarians.

\section{Limitations}

Due to the fact that BCI solutions are not yet implemented in libraries and are rarely the subject of scientific considerations in the field of library and information science, this article is mainly based on literature from other disciplines. The goal was to consider how much BCI solutions can affect library information retrieval systems. The considerations presented in this article are theoretical in nature due to the lack of empirical materials on which to base. The author's assumption was to initiate a discussion about BCI on the basis of library and information science, not to propose final solutions.

\section{References}

Abdulkader, S.N., Atia, A. and Mostafa, M.-S.M. (2015), "Brain computer interfacing: applications and challenges", Egyptian Informatics Journal, Vol. 16 No. 2, pp. 213-230.

Angrisani, L., Arpaia, P., Moccaldi, N. and Esposito, A. (2018), "Wearable augmented reality and brain computer interface to improve human-robot interactions in smart industry: a feasibility study for SSVEP signals", 2018 IEEE 4th International Forum on Research and Technology for Society and Industry (RTSI), IEEE, Piscataway, pp. 1-5.

Avila, S. (2017), "Implementing augmented reality in academic libraries", Public Services Quarterly, Vol. 3, pp. 190-199.

Boateng, F.F. and Liu, Y.Q. (2014), "Web 2.0 applications' usage and trend $\mathrm{s}$ in top US academic libraries”, Library Hi Tech, Vol. 32 No. 1, pp. 120-138.

Burwell, S., Sample, M. and Racine, E. (2017), "Ethical aspects of brain computer interfaces: a scoping review", BMC Medical Ethics, Vol. 18 No. 1, available at: https://bmcmedethics.biomedcentral. com/articles/10.1186/s12910-017-0220-y\#citeas (accessed 18 August 2019).

ChanLin, L.-J. and Hung, W.-H. (2016), "Usability and evaluation of a library mobile web site", The Electronic Library, Vol. 34 No. 4, pp. 636-650.

Chaudhary, U., Birbaumer, N. and Ramos-Murguialday, A. (2016), "Brain-computer interfaces for communication and rehabilitation", Nature Reviews Neurology, Vol. 12 No. 9, pp. 513-525.

Chaudhary, U., Mrachacz-Kersting, N. and Birbaumer, N. (2020), "Neuropsychological and neurophysiological aspects of brain-computer-interface (BCI) control in paralysis", The Journal of Physiology, pp. 1-7, doi: 10.1113/JP278775 (accessed 30 December 2020).

Chow, A.S. and Croxton, R.A. (2014), "A usability evaluation of academic virtual reference services", College and Research Libraries, Vol. 75 No. 3, pp. 309-361.

Garcia, L., Lespinet-Najib, V., Saioud, S., Meistermann, V., Renaud, S., Diaz-Pineda, J., Marc André, J. and Ron-Angevin, R. (2015), "Brain-computer interface: usability evaluation of different P300 speller configurations: a preliminary study", International Work-Conference on Artificial Neural Networks, Springer, Cham, pp. 98-109. 
LHT 40,6
Gupta, S. (2018), "Evaluation of next generation online public access catalogue (OPAC) features in library management system”, Library Waves-A Biannual Peer Reviewed Journal, Vol. 4 No. 1, pp. 43-50.

Gupta, Y., Saini, A. and Saxena, A.K. (2015), "A new fuzzy logic based ranking function for efficient information retrieval system", Expert Systems with Applications, Vol. 42 No. 3, pp. 1223-1234.

Hortal, E., Planelles, D., Costa, A., Iáñez, E., Úbeda, A., Azorín, J.M. and Fernández, E. (2015), "SVMbased Brain-Machine Interface for controlling a robot arm through four mental tasks", Neurocomputing, Vol. 151, pp. 116-121.

Ienca, M. and Haselager, P. (2016), "Hacking the brain: brain-computer interfacing technology and the ethics of neurosecurity”, Ethics and Information Technology, Vol. 18 No. 2, pp. 117-129.

Kang, H.J., Kim, D.H., Kim, B.M., Oh, D. and Jang, S.B. (2016), "Design and implementation of a threedimensional game based on a brain-computer interface", International Journal of Advanced Science and Technology, Vol. 95, pp. 73-88.

Kauppinen, H., Ahonen, R., Mäntyselkä, P. and Timonen, J. (2017), "Medication safety and the usability of electronic prescribing as perceived by physicians-a semistructured interview among primary health care physicians in Finland", Journal of Evaluation in Clinical Practice, Vol. 23 No. 6, pp. 1187-1194.

Koskela, T., Sandström, S., Mäkinen, J. and Liira, H. (2015), "User perspectives on an electronic decision-support tool performing comprehensive medication reviews-a focus group study with physicians and nurses”, BMC Medical Informatics and Decision Making, Vol. 16 No. 1, p. 6, available at: https://bmcmedinformdecismak.biomedcentral.com/articles/10.1186/s12911-0160245-z (accessed 10 September 2019).

Krishna, G. (2015), The Best Interface Is No Interface: The Simple Path to Brilliant Technology, Pearson Education, San Francisco.

Krug, S. (2014), Don't Make Me Think, Revisited : A Common Sense Approach to Web Usability, Berkeley, New Riders.

Lawhern, V.J., Solon, A.J., Waytowich, N.R., Gordon, S.M., Hung, C.P. and Lance, B.J. (2018), "EEGNet: a compact convolutional neural network for EEG-based brain-computer interfaces", Journal of Neural Engineering, Vol. 15 No. 5, pp. 1-32, doi: 10.1088/1741-2552/aace8c.

Limberg, L., Sundin, O. and Talja, S. (2012), "Three theoretical perspectives on information literacy", Human IT: Journal for Information Technology Studies as a Human Science, Vol. 11 No. 2, pp. 93-130.

Mason, S.G. and Birch, G.E. (2003), "A general framework for brain-computer interface design”, IEEE Transactions on Neural Systems and Rehabilitation Engineering, Vol. 11 No. 1, pp. 70-85.

Merrill, N. and Chuang, J. (2018), "From scanning brains to reading minds: talking to engineers about brain-computer interface", Proceedings of the 2018 CHI Conference on Human Factors in Computing Systems, Association for Computing Machinery, New York, pp. 1-11.

Monaco, A., Sforza, G., Amoroso, N., Antonacci, M., Bellotti, R., de Tommaso, M., Di Bitonto, P., Di Sciascio, E., Diacono, D., Gentile, E., Montemurno, A., Ruta, M., Ulloa, A. and Tangaro, S. (2019), "The PERSON project: a serious brain-computer interface game for treatment in cognitive impairment”, Health Technology, Vol. 9 No. 2, pp. 123-133.

Nielsen, J. (1994), "Heuristic evaluation", Usability Inspection Methods, Wiley \& Sons, New York, pp. 25-62.

Olsson, T., Kärkkäinen, T., Lagerstam, E. and Ventä-Olkkonen, L. (2012), "User evaluation of mobile augmented reality scenarios", Journal of Ambient Intelligence and Smart Environments, Vol. 4 No. 1, pp. 29-47.

Orenda, M.P., Garg, L. and Garg, G. (2017), "Exploring the feasibility to authenticate users of web and cloud services using a brain-computer interface (BCI)", International Conference on Image Analysis and Processing, Springer, Cham, pp. 353-363.

Parkes, D. and Walton, G. (Eds) (2010), Web 2.0 and Libraries: Impacts, Technologies and Trends, Chandos, London. 
Pichiorri, F., Morone, G., Petti, M., Toppi, J., Pisotta, I., Molinari, M., Paolucci, S., Inghilleri, M., Astolfi, L., Cincotti, F. and Mattia, D. (2015), "Brain-computer interface boosts motor imagery practice during stroke recovery", Annals of Neurology, Vol. 77 No. 5, pp. 851-865.

Priestner, A. and Borg, M. (2016), UX in Libraries. User Experience in Libraries: Applying Ethnography and Human-Centred Design, Routledge, New York, London.

Ramadan, R.A. and Vasilakos, A.V. (2017), "Brain computer interface: control signals review", Neurocomputing, Vol. 223, pp. 26-44.

Ramakuri, S.K., Ghosh, S. and Gupta, B. (2017), "Behaviour state analysis through brain computer interface using wearable EEG devices: a review", Electronic Government, An International Journal, Vol. 13 No. 4, pp. 377-390.

Reason, B., Løvlie, L. and Flu, M. (2015), Service Design for Business, Wiley, Hoboken.

Rosenfeld, J.V. and Wong, Y.T. (2017), "Neurobionics and the brain-computer interface: current applications and future horizons", Medical Journal of Australia, Vol. 206 No. 8, pp. 363-368.

Siroker, D. and Koomen, P. (2013), A/B Testing: The Most Powerful Way to Turn Clicks into Customers, John Wiley \& Sons, Hoboken.

Sullivan, L.S. and Illes, J. (2016), "Beyond 'communication and control': towards ethically complete rationales for brain-computer interface research", Brain-Computer Interfaces, Vol. 3 No. 3, pp. 156-163.

Vasiljevic, G.A.M., de Miranda, L.C. and de Menezes, B.C. (2018), "Mental war: an attention-based single/multiplayer brain-computer interface game", International Conference on Computational Science and Its Applications, Springer, Cham, pp. 450-465.

Vansteensel, M.J., Pels, E.G., Bleichner, M.G., Branco, M.P., Denison, T., Freudenburg, Z.V., Gosselaar, P., Leinders, S., Ottens, T.H., Van Den Boom, M.A., Van Rijen, P.C., Aarnoutse, E.J. and Ramsey, N.F. (2016), "Fully implanted brain-computer interface in a locked-in patient with ALS", New England Journal of Medicine, Vol. 375 No. 21, pp. 2060-2066.

Verkijika, S.F. (2015), "Assessing the use of a brain-computer interface (BCI) in mathematics education: the case of a cognitive game", Diss. University of the Free State, available at: https:// scholar.ufs.ac.za/handle/11660/1440 (accessed 21 September 2019).

Welton, T., Brown, D.J., Evett, L. and Sherkat, N. (2016), "A brain-computer interface for the Dasher alternative text entry system”, Universal Access in the Information Society, Vol. 15 No. 1, pp. 77-83.

Weyand, S., Schudlo, L., Takehara-Nishiuchi, K. and Chau, T. (2015), "Usability and performanceinformed selection of personalized mental tasks for an online near-infrared spectroscopy braincomputer interface", Neurophotonics, Vol. 2 No. 2, available at: https:/www.spiedigitallibrary.org/ journals/Neurophotonics/volume-2/issue-2/025001/Usability-and-performance-informed-selectionof-personalized-mental-tasks-for/10.1117/1.NPh.2.2.025001.full (accessed 8 August 2019).

Young, S. and Rossmann, D. (2015), "Building library community through social media", Information Technology and Libraries, Vol. 34 No. 1, pp. 20-37.

\section{About the author}

Magdalena Wójcik ( $\mathrm{PhD}$ ) Iam an assistant professor at the Jagiellonian University, Kraków (Poland). Iam interested in new technologies, particularly Web 2.0, augmented reality, wearable computing and Internet of Things and their impact on libraries' services. Some of my publications are: The Use of Web 2.0 Services by Urban Public Libraries in Poland: Changes over the Years 2011-2013. Libri, Vol. 65, Issue 2, pages 91-103, Potential use of Augmented Reality in LIS education. Education and Information Technologies, 21(6), pages 1555-1569, Internet of Things - potential for libraries, Library Hi Tech, Vol. 34, Issue 2, pages 404-420 and Holograms in libraries-the potential for education, promotion and services. Library Hi Tech 36.1, pages 18-28. Magdalena Wójcik can be contacted at: magda.wojcik@uj.edu.pl

For instructions on how to order reprints of this article, please visit our website:

www.emeraldgrouppublishing.com/licensing/reprints.htm

Or contact us for further details: permissions@emeraldinsight.com 